\title{
Addressing transgender discrimination in health
}

$\mathrm{T}$ he United States government has proposed new rules to prevent medical providers and insurers from discriminating against transgender patients. The rules would forbid insurers from categorically denying coverage of services related to gender transition.

"We propose that discrimination on the basis of sex further includes discrimination on the basis of gender identity," state the proposed rules. The Department of Health and Human Services will consider adopting the new rules after a 60-day public comment period that ends Nov. 6 .

When reached for comment, the USbased National Center for Transgender Equality referred $C M A J$ to a press release that said the proposed rules "have the potential to be life-saving for transgender people," who will now be able to "find affordable health insurance that covers the essential care they need and doesn't exclude care simply because of who they are."

Though discrimination against transgender patients in health care may not be as overt in Canada as in the US, it still exists in several forms, according to Jordan Zaitzow, coordinator of Trans Health Connection for Rainbow Health Ontario. For example, some transgender patients believe provincial governments discriminate against them when deciding which services are medically necessary as opposed to merely cosmetic. Mastectomies and sex reassignment surgeries may be covered, but male chest contouring and voice therapy are not.

"There is at that level still quite a bit of discrimination," said Zaitzow.

Transgender patients also feel they are often denied care by primary care physicians who claim it is outside their scope of practice. According to Zaitzow, primary care for transgender patients is mostly regular care, and generally not exceptional.

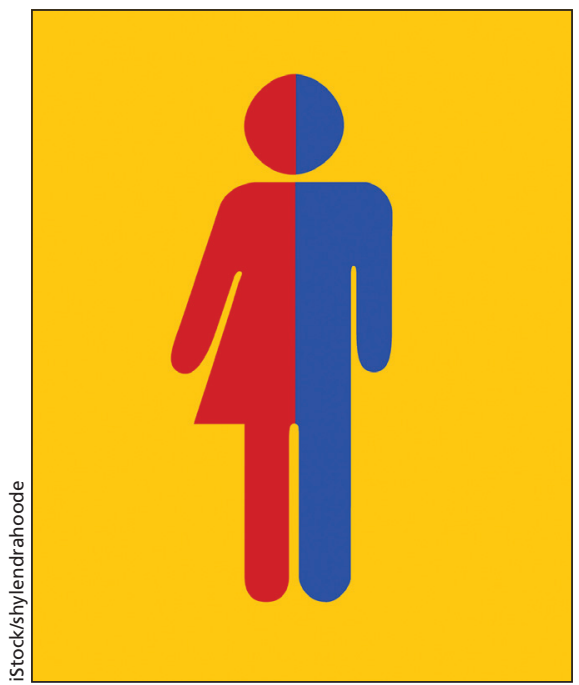

Ensuring health facilities have genderneutral washrooms is one way to help transgender patients feel more welcome.

"I consider that kind of denial of services to be, sort of abstractly, transphobia," said Zaitzow.

Another form of discrimination occurs when medical providers pepper transgender patients with questions unrelated to the health matter at hand, according to Nicole Nussbaum, past president of the Canadian Professional Association for Transgender Health. Some patients have recalled incidents during which medical providers focused too much on their being transgender, asking intrusive and irrelevant questions instead of providing the necessary care.

"They are being sort of interrogated about their gender and their genderidentity and their history," said Nussbaum. "If you skin your knee and you might need stitches, what does that have to do with anything else?"

Some forms of discrimination in health care are subtle yet can contribute to unease and emotional distress for transgender patients, said Thomas Sasso, a PhD student in industrial-organizational psychology at the University of Guelph who has researched lesbian, gay, bisexual, transgender and queer discrimination in the workplace. This could include the lack of a gender-neutral washroom or failure to use a patient's chosen name or preferred pronoun.

"Sometimes we get so focused on the body, we forget that health also encompasses the mind, our emotions and our mental health," said Sasso.

Addressing transgender health discrimination in Canada may require a different approach than in the US. Canada does not have countless medical insurers, each with its own policies dictating who and what they will cover, so a new federal law may not be necessary. Also, the rights of transgender Canadians to equitable health care are covered, in theory, by human rights legislation. Medical facilities, however, can indeed make changes to improve care for transgender patients.

This would include, first and foremost, creating a nonoppressive environment that is respectful of the unique needs of transgender patients, said Deanna Clatworthy, clinic coordinator for HIV/AIDS Resources \& Community Health $(\mathrm{ARCH})$ clinic in Guelph, Ontario. The ARCH clinic recently opened a transgender health clinic that offers primary care, hormone replacement therapy, referrals for sex reassignment surgery and other services.

Improving care for transgender patients might also include providing diversity training for medical staff, noted Clatworthy. That could help ensure transgender patients are referred to in a respectful manner in accordance with their self-identities, regardless of the names on their health cards. "For billing, you have to use the name on the health card, but just because that's the name sent to the government doesn't mean you have to use that when referring to the patient." - Roger Collier, CMAJ

CMAJ 2015. DOI:10.1503/cmaj.109-5158 